\title{
Adult Participation in Self-Directed Learning Programs
}

\author{
Muhammad Madi Bin Abdullah (Corresponding author) \\ College of Business Management and Accounting \\ Universiti Tenaga Nasional, Sultan Haji Ahmad Shah Campus \\ 26700 Bandar Muadzam Shah, Pahang, Malaysia \\ Tel: 60-9-455-2000Ｅ-mail: madi@uniten.edu.my \\ Sebastian Francis Koren \\ Department of Professional Development and Continuing Education, \\ Faculty of Educational Studies, Universiti Putra Malaysia \\ 43400 UPM Serdang, Selangor, Malaysia \\ E-mail: seb28koren@yahoo.com \\ Balakrishnan Muniapan \\ School of Business \\ Swinburne University of Technology, Sarawak, Malaysia \\ Jalan Simpang Tiga, 93576 Kuching, Sarawak, Malaysia \\ E-mail: mbalakrsna@yahoo.com \\ Balakrishnan Parasuraman \\ School of Social Sciences \\ Universiti Malaysia Sabah \\ Locked Bag No. 2073, 88999, Kota Kinabalu, Sabah, Malaysia \\ Email: bala@ums.edu.my \\ Balan Rathakrishnan \\ School of Psychology and Social Work \\ Universiti Malaysia Sabah, Kota Kinabalu \\ Locked Bag No. 2073, 88999, Kota Kinabalu, Sabah, Malaysia \\ E-mail: balanratha@yahoo.com
}

\begin{abstract}
This paper attempts to explain the various concepts related to self-directed learning and also the various theories and models regarding adult participation and also non-participation in self-directed learning programs. Because of the extensive amount of previous literature and research findings dealing with self-directed learning, it is necessary to synthesize the relevant literature so that it can be useful as a basis for this and also for further research in this field. Conceptualization of self-directed learning will be reviewed in the wider and broader perspective. Also reviewed will be the development of self-directed learning, the definitions and characteristics of self-directed learning. Different conceptualization and factors contributing to adult participation in self-directed learning will be touched. In order to design an instrument and to develop a conceptual model, which adequately reflects those factors that have been reasonably determined to be relevant, it is felt that there was a need to identify those variables or factors, reported in earlier studies, which have been found to be significantly associated with adult participation in self-directed learning.
\end{abstract}

Keywords: Self-directed learning, Adult participation, Distance learning programs

\section{Introduction}

In 1961, Cyril Houle commented, adult learners are goal oriented, activity oriented or learning oriented. Malcom Knowles (1970) in his book entitled 'Modern Practice of Adult Education' postulates that adults are self-directed in other areas of their lives, and therefore they prefer self-directed learning. He also presented with the assumptions of 
andragogy, which explain the characteristics of adult learners. From 1971 to 1979 Allen Tough with his famous 'Adult Learning Projects' did an extensive research on 'adult self-learners', especially focusing on how they learn, how many learning projects they complete on their own per year and also the resources they used for learning. The study found that, median of eight learning projects per year and seventy percent were self-planned. In the year of 1989, Sandra McCune in her study entitled 'A Meta-analytic Study of Self-direction in Adult Learning' identified most frequently used research tools (Guglielmino's SDLRS and Tough's interview schedule). She also verified a variety of variables associated with self-direction in learning across studies using different methodologies.

In 1984, Lorys Oddi developed an instrument to measure self-directed and continuing learning of professionals (Oddi Continuing Learning Inventory). Breckett and Hiemstra in 1991 came out with a 'Personal Responsibility Orientation Model' which suggests individuals taking responsibility for their own learning is central. According to them, self-directed learning can be seen as both an instructional method (self-directed learning) and a personality characteristic (learner self-direction). They also further lamented, the 'social context' in which the learning itself takes place is also important. Gerald Grow developed a model of four stages of readiness for self-direction learning in 1991 and followed by a self-direction learning perception by Jane Pilling-Cormick in 1996. In 1996, Gary and Sharon developed another learner profile called 'Learner Autonomy Profile'.

In 1988, Caffarela and O'Donnell introduced five categories of self-direction in learning. The first was on the nature of the philosophical perspective of the process (conceptual perspective of the process). The second was on the verification studies (descriptive investigations of learning process) followed by the nature of the method of self-directed learning. Nature of the individual learner was the fourth category and the final category was about policy questions. Merriam and Caffarella in 1999 looked at self-directed learning on three broad categories. The first category is related to goals of self-directed learning. Second is examining self as a process or form of study. The third category is considering self as a personal attribute of the learner.

In sum, the earlier research considered to be less interactive and found to be guided by linear model approaches which move from diagnosing needs to identifying resources and instructional formats to evaluation outcomes. The previous studies mainly focus on the three important aspects of adult learning. They are the goals, the process and the learner itself. The work of Merriam and Caffarella, which open the eyes of the adult learners and the adult educators especially explained the development of the learners' capacity to be self-directed, fostering of the transformational learning and also the promotion of emancipatory learning and social actions (social context). From teacher- centered approach in pedagogy the dimension of adult learning moves into a new paradigm of learner-centered approach in andragogy. The adult learners have more control and authority of their own learning and they are responsible for all their personal learning. Self-directed learning becomes an important aspect in the adult lifelong learning. They want to plan their own learning activities. They also want to have a full control of their personal learning and also the resources they choose for their various learning activities. In final, the adults have more power in creating their own path in the journey of continuous learning throughout their life.

\section{Self-Directed Learning}

Caffarella (1993) have commented that, self-directed learning has contributed to our understanding of learning by identifying an important form of adult learning and providing insights into the process of learning, challenging to define and debate the salient characteristics of adult learners and expanding the thinking about learning in formal settings. She further lamented, self-directed learning does not necessarily mean solitary learning or isolation. Rather, the adults in this type of learning seek assistance in the form of human and material resources like friends, colleagues, experts in the content areas, books, magazines, journals and other audio-visual materials.

Knowles (1975) has identified self-directed learning is often been used to describe as a form of study in which people take the primary initiative, with or without the help of others, for planning, conducting, and evaluating their own learning activities. Merriam and Caffarella (1991) pointed out that self-directed learning is a form of study in which learners have the primary responsibility for planning, carrying out, and evaluating their own learning experiences. Kasworm (1983b) cited in Merriam and caffarella (1991) proposes that self-directed learning "represents a qualitative evolvement of a person's sense of cognitive definition and developmental readiness for ambiguous and non-defined actions". Chene (1983) offers three elements that characterize an autonomous or self-directed learner: independence, the ability to make choices, and the capacity to articulate the norms and the limits of a learning activity.

Based on the ongoing works on self-directed learning, Knox (1986) identifies several characteristics of adult learners that can enable educators to plan and organize learning activities around adults' background and aspirations whether in the formal or non-formal situations. These characteristics may be grouped under four categories: enhancing proficiencies, development and learning, influences on participation, and the importance of active learner participation. Rogers (1986) delineates four characteristics of this adult natural learning process. Firstly, this form of learning may not be continuous, i.e., episodic in nature depending sometime on whether the purpose is achieved. Secondly, the learning goal is usually concrete or to solve some immediate problem of importance. Thirdly, in pursuing self-directed learning, 
each adult adopts one own learning style and a range of strategies employed is typical of adults than by other group of learners. Fourthly, since self-directed learning is directed toward specific goals, adult learning tends to focus on how to cope with the particular situation rather than the general principles. Merriam and Caffarella (1991) mentioned that Tough and Knowles were among the pioneers to describe how adults go about learning on their own and elaborate on the key decision making points about choosing what, where and how to learn. They were the first to urge that learner self-direction be incorporated into organized learning for adults. Greater learner control means that learners are given the time and opportunity to think about what they want to learn (that is meaningful or useful to them), how they want to go about learning (techniques, resources needed, location, and pacing), and which criteria will be used, and in what ways, to determine whether the learning experience was satisfactory and worthwhile.

Brockett et al (1991) provided with distinct ideas that incorporated the concept of self-directed learning; a self-initiated process of learning that stresses the ability of individuals to plan and manage their own learning, an attribute or characteristic of learners with personal autonomy as its hallmark, and a way of organizing instruction formal settings that allows for greater learner control. They also have suggested that the focus of learning is on the individual and self-development, with learners expected to assume primary responsibility for their own learning. The process of learning, which is centered on learner need, involved in the learning process, their most important role is to act as facilitators or as guides, as opposed to content experts.

\section{Theories of Self-Directed Learning}

Knowles (1975) mentioned that, underlying all attempts to engage adults in self-directed learning are the beliefs that (a) self-directed adults will learn more, learn better, retain, and make better of learning than do reactive learners; (b) effective adult living requires lifelong, continuous, effective, and creative self-guided learning; and (c) the motivations, attitudes, inner resources, and skills needed to engage in this lifelong learning can be developed and enhanced by participating in well-designed learning situations that give the opportunity to practice them in conscious way. Also underlying these programs is the hope that self-directing adults to gain greater control over their own destines both in their personal lives and in society (Herman, 1982).

Knowles (1975) compares the assumption on which self-directed learning is based with those of teacher-directed learning in the areas of concept of the learner, role of the learner's experience, readiness to learn, orientation to learning, and motivation. He makes similar comparisons on "process elements" of climate, planning, diagnosing needs, setting goals, designing a learning plan, learning activities, and evaluation. Boud (1981) made a clear statement of working assumptions as a composite from his own work and his study of a number of programs in several countries. His list of assumptions is divided into three groups; the nature of autonomous learning, characteristics of students, and role of teachers.

Gugilielmo (1977) cited in Griffin ( 1989) has developed a self-directed learning readiness scale, reflecting eight factors: openness to learning opportunities, self-concept in an effective learner, initiative and independence in learning, informed acceptance of responsibility for one's own learning, love of learning, creativity, future orientation, and ability to use basic study skills and problem-solving skills.

Taylor (1981) reports her findings that adult learners in a self-directed learning course experienced four phases in their learning: detachment, divergence, engagement, and convergence; these four phases contain ten critical points in the learning process. According to Brookfield (1986), "The most fully adult form of self-directed learning...is one in which critical reflection on the contingent aspects of reality, the exploration of alternative perspectives and meaning systems, and the alteration of personal and social circumstances are all present." Hammons and Collins (1991) cited in Merriam (1993) operationalized this critical learning notion of critical practice. They emphasize reflective thinking as a key part of each component of their model as well as include within their "analysis" component an in-depth look at the "structure and functioning of the society in which we work" so that learners can better understand and respond to the context that, at least in part, shapes what and how they learn.

\section{Adult Participation Theories}

The central assumption is that learning in adulthood means growth in self-direction and autonomy (Candy 1991; Chene 1983; Kasworm 1983; Knowles 1980) cited in Merriam (1999). One of the four major tenets of andragogy is "the adults have a deep psychological need to be generally self-directing". The learner characteristic of adults has become for many adult educators, including self-directed distance learning program providers one of the major goals of their instructional processes; allowing and, in some cases, teaching adults how to take more responsibility and control in the learning process. These two theories are generally emphasized on the adult's life situation- about their experiences, roles and responsibilities. Arshad (1993) asserts that these particular four theories perhaps reveal more about the true characteristic and the motives for participation in adult self-directed learning or continuing education.

There are many studies of motivation for participation in adult education view it as defined by the goals adult learners hope to reach by means of participation, such as job advancement, acquisition of a new skill, or development of new 
friendships ( Houle 1961; Courtney 1991; Cross 1981; Collins 1985). The question of participation in adult learning programs especially focusing on self-directed learning programs then becomes a matter not of ascertaining what it is that the adults want to learn or what teaching and learning strategies are most suitable in view of the special characteristics of adult learners, but rather of establishing which factors dispose some people to regard adult education as a good thing, others to see it as irrelevant to their lives, or boring, or snobbish.

To answer the question "why" adults participate in self-directed learning programs needs an understanding of adult learning motivation. This requires a closer look into several learning theories namely Andragogy Theory, Characteristics of Adult Learners Theory, Margin Theory and Proficiency Theory. The first two theories, Knowles' Andragogy and Cross's Characteristics of Adult Learners can be categorized as adult learners' characteristics theories. Knowles' (1980) theory was based upon certain assumptions, all of which are characteristics of adult learners as follows:

- Adults are autonomous and self-directed. They need to be free to direct themselves. Their teachers must actively involve adult participants in the learning process and serve as facilitators for them. Specifically, they must get participants' perspectives about what topics to cover and let them work on projects that reflect their interests. They should allow the participants to assume responsibility for presentations and group leadership. They have to be sure to act as facilitators, guiding participants to their own knowledge rather than supplying them with facts.

- Adults have accumulated a foundation of life experiences and knowledge that may include work-related activities, family responsibilities, and previous education. They need to connect learning to this knowledge/experience base. To help them do so, they should draw out participants' experience and knowledge which is relevant to the topic. They must relate theories and concepts to the participants and recognize the value of experience in learning.

- Adults are goal-oriented. Upon enrolling in a course, they usually know what goal they want to attain. They, therefore, appreciate an educational program that is organized and has clearly defined elements. Instructors must show participants how this class will help them attain their goals. This classification of goals and course objectives must be done early in the course.

- Adults are relevancy-oriented. They must see a reason for learning something. Learning has to be applicable to their work or other responsibilities to be of value to them. Therefore, instructors must identify objectives for adult participants before the course begins. This means, also, that theories and concepts must be related to a setting familiar to participants. This need can be fulfilled by letting participants choose projects that reflect their own interests.

- Adults are practical, focusing on the aspects of a lesson most useful to them in their work. They may not be interested in knowledge for its own sake. Instructors must tell participants explicitly how the lesson will be useful to them on the job.

- As do all learners, adults need to be shown respect. Instructors must acknowledge the wealth of experiences that adult participants bring to the classroom. These adults should be treated as equals in experience and knowledge and allowed to voice their opinions freely in class.

Boshier and Collins (1985) suggested that a six-factor model was the most theoretically and psychometrically defensible in understanding the need for adults participating in any form of adult learning including self-directed learning programs. According to them, the adult participants were deemed to enroll or participate because of a need for:

- Social contact: these participants want to make and consolidate friendships, to be accepted by others, to gain insight into personal problems, to improve relationships and their social position. They participate because of their need for group activities and congenial friendships.

- Social stimulation: participants enrolled for this factor want to get relief from boredom, overcome the frustration of day-to-day living, to escape intellectual narrowness, to have a few hours away from other responsibilities. The essence of the factor is the use of adult education as an escape from boredom or frustration.

- Professional advancement: participants enrolled for this factor want to secure professional advancement, higher status in their job, or knowledge that will help in other courses. They are primarily job oriented.

- Community service: participants enrolled for this factor want to become more effective as citizens, to prepare for community service, to gain insight into human relationships, and to improve their ability to participate in community work.

- External expectations: participants enrolled for this factor are complying with the instructions of someone else. They are enrolled on the recommendation of some authority who is usually an employer, social worker, friend, religious head or counselor.

- Cognitive interest: participants enrolled for this factor enjoy learning for its own sake. They merely want to "satisfy an enquiring mind" or "seek knowledge for its own sake".

Cross (1981) postulated the CAL theory. This theory was mainly based upon two categories of variables, personal 
characteristics and situational characteristics. The personal characteristics include the psychological stages. These were presented along a continuum, which reflects growth from childhood to adulthood. The situational characteristics on the other hand, focuses on variables that unique to the adult's participation in self-directed learning activities namely, part-time versus full-time versus compulsory participation. The adult learning is therefore based on the interactions of these two variables. Generally, the theory was considered comprehensive and holistic in explaining "what and how" adults learn, but the variables were broadly defined and it has yet to be empirically tested (Merriam and Caffarella, 1991).

Mc Clusky's Margin theory cited in Merriam (1991) assumes that the adult's "load of life" needs to be balanced-up with the adult's "power of life". Load of life here represents the adult's development, roles, problems and various other responsibilities. Power of life refers to the knowledge and skills that an individual needs in life. If power of life is greater than the load of life, there is a "margin in life".

Knox (1980) defines "proficiency" as "the capability to perform satisfactorily if given the opportunity". This performance in all tasks involves same combination of attitude, knowledge and skill. Adult motivation and achievement in both learning activities and life roles depend largely upon the discrepancy between the current and the desired level of proficiency. The purpose of adult learning is therefore to enhance proficiency in order to improve performance and effectiveness.

\section{Barriers to Participation}

Within the literature of adult learning a good deal of attention has been given to 'non-participation' as well as to 'participation'. As McGiveney (1993) comments, a common finding in participation research is that non-participants have little or no knowledge of the educational opportunities available. One way of looking at some of the barriers to participation is to differentiate between situational, institutional and dispositional factors as discussed further. These are called the perceived barriers to learning according to Smith (2002) in his article entitled "participation in learning projects and programs". He provided the following barriers;

(1) Situational barriers: those arising from one's situation at a given time.

- Lack of money- the cost of studying, the cost of child care and so on.

- Lack of time, for example, because of job and home responsibilities.

- Lack of transport to study venue.

(2) Institutional barriers: those practices and procedures that exclude or discourage adults from participating in learning activities.

- Inconvenient schedules or locations for programs

- Lack of relevant or appropriate programs

- The emphasis on full-time study in many institutions.

(3) Dispositional barriers: those related to attitudes and self-perceptions about

oneself as a learner.

- Feeling 'too old' to learn.

- Lack of confidence because of 'poor' previous educational achievements.

- Tired of school, tired of classrooms (Cross, 1981).

Scanlan and Darkenwald (1984) cited in Cervero (1988) studied a statewide sample of physical therapists, medical technologists, and respiratory therapists, and, using the statistical procedure of factor analysis, found six types of deterrents to adult participation in self-directed learning activities. Akintade (1985) cited in Cervero (1988) also obtained similar results with two statewide samples of social workers. In Scanlan and Darkenwal's study (1984) cited in Cervero (1988), the first deterrent was labeled disengagement and reflected a general apathy toward participating in self-directed learning programs. The second deterrent denoted a general dissatisfaction with the quality of available programs and was called lack of quality. The third deterrent, family constraints, relates to adults' extra-occupational responsibilities, such as parenting. The cost of attending programs was the fourth deterrent identified. The fifth type of deterrent was that adults failed to see the relative worth of participating in adult education; it was labeled lack of benefit. The sixth reflected the conflicting demands on adults' work time, particularly scheduling difficulties, and was called work constraints.

\section{Conclusion}

Much of the research done on self-directed learning activity particularly related to successful E-learners suggests that adult students who are attracted to this type of learning share certain common characteristics, including that they are 
voluntary seeking further education, are highly motivated, have high expectations, are more self-disciplined, are independent, are active learners, possess good organizational and time management skills, and can adapt to the new learning environments. They tend to be older than the average student do and have a more serious attitude towards their courses, education and learning. They are working more flexible schedules. They are not necessarily looking for campus-based educational and social opportunities. Consequently, they bring with them a different set of assets and expectations to the learning process (Lyman, 1999; Palloff and Pratt, 2001; Willis,1993). A comprehensive questionnaire on motivating factors in E-learning was designed by Kamal and Lee (2003) to obtain views of adult students pursuing degrees from University Tun Abdul Razak (UNITAR). The empirical research done for this study revealed that the top five motivating factors in choosing self-directed learning program through E-learning course were as follows: (a) It fulfills the need for increased flexibility; (b) It fulfills the need for geographical independence; (c) Web-based environment can potentially offer many opportunities for enriching the adult learning process-can have the world at your fingertips; (d) E-learning suits the rapidly changing nature of knowledge; and (e) E-learning offers temporal independence (learning can be done anytime convenient to the students).

\section{References}

Arshad, Hashim (1993). Correlates of public employees motivational orientations and motivation towards in-service training in Malaysia. Unpublished Doctoral Dissertation, Center for Extension and Continuing Education, Universiti Putra Malaysia.

Boshier, R. and Collins, J.B. (1985). The Houle Typology After Twenty-Two Years: A Large Scale Empirical Test. Adult Education Quarterly, 113-130.

Boud, C. (1981). Developing Student Autonomy In Learning. London. Kogan Page.

Brockett, R.G. and Hiemstra, R. (1991). Self-Direction in Adult Learning: Perspectives on Theory, Research, and Practice. London and New York: Routledge \& Kegan Paul.

Brookfield, S. (1986). Understanding and Facilitating Adult Learning. San Francisco: Josey-Bass.

Caffarella, R. S. (1993). Self-directed learning. In S.B. Merriam (ed), An Update on adult learning theory, no.57.San Francisco:Jossey-Bass.

Caffarella, R. S. and O'Donnell, J.M. (1988). Self-directed learning. Nottingham, England: Department of adult education, University of Nottingham.

Cervero, R. M. (1988). Effective Continuing Education for Professionals. San Francisco: Jossey-Bass.

Chene, A. (1983). The concept of autonomy: A philosophical discussion. A dult Education Quarterly. 38-47.

Collins, M. (1988). Self-directed learning or an emancipatory practice of adult education: Re-thinking the role of the adult educator. Proceedings of the adult education research conference. University of Calgary, Calgary.

Courtney, S. (1991). Why Adults Learn: Toward a Theory of Participation in Adult Education. New York: Routledge, Chapman \& Hall.

Cross, K. P. (1981). New Frontiers for Higher Education: Business and the Professions. In American Association for Higher Education (ed.), Partnerships with Business and the Professions. Washington, D. C.: American Association for Higher Education.

Darkenwald, G. G. and Merriam S. B. (1993). Adult Education: Foundations of Practices. New York: Harper and Row Publishers Inc.

Grow, G. (1991). Teaching Learners to be self-directed: A stage approach. A dult Education Quarterly. 125-149.

Herman, R. (ed) (1982). The Design of Self-Directed Learning: A Handbook for Teachers and Administrators, rev. edn. Department of Adult Education, Ontario Institute for studies in Education, Toronto, Ontario.

Houle, C. O. (1961). The Inquiring Mind. Madison: University of Wisconsin Press.

Kamal and Lee. (2003). Motivating Factors in E-Learning: A Case Study of UNITAR. Malaysia.

Knowles, M. S. (1975). Self-directed Learning. New York: Association Press.

Knowles, M. S. (1980). The Modern Practice of Adult Education: From Pedagogy to Andragogy. (2 ${ }^{\text {nd }}$ ed.). New York: Cambridge Books.

Knox, A. B. (1980). Proficiency Theory of Adult Learning. Contemporary Educational Psychology. 378-404.

Knox, A. B. (1986). Helping Adults Learn. San Francisco: Jossey-Bass.

Lyman, B. (1999). Internet-based learning: What is in it for the adult learner? In D. French, C.Hale, C. Johonson, \& G. Farr (Ed.), Internet-base learning: An Introduction and framework for higher education and business. 25-46. New York: 
Kogan.

McCune, S. N. (1988). A Meta-Analytic Study of Adult Self-Direction in Learning: A Review of Research from 1977 to 1987. Doctoral Dissertation, Department of Interdiciplinary studies, Texax A\&M University.

McGiveney, V. (1993). Women, Education and Training. Barriers to access, informal starting points and progression routes, Leicester: National Institute of Adult Continuing Education.

Merriam, S. B. and Caffarella, R. S. (1991). Learning in adulthood: A comprehensive guide. San Francisco: Jossy-Bass.

Oddi, L. F. (1984). Development of an instrument to measure self-directed continuing learning. Doctoral dissertation, Northern Illinois University.

Palloff, R. M. \& Pratt, K. (2001). Lessons from the cyberspace classroom: The realities of online teaching. San Francisco: Jossey-Bass.

Rogers, A. (1986). Teaching Adults. Milton Kaynes, England: Open University Press.

Taylor, M. (1981). The Social Dimension of Adult Learning. In: Salter L (ed.). Communication Studies in Canada. Butterworth. Toronto, Ontario, 133-146.

Tough, A. (1979). The Adult's Learning Projects: A Fresh Approach to Theory and Practice in Adult Learning ( $2^{\text {nd }}$ ed. ). Toronto, Ontario, Canada: Ontario Institute for Studies in Education.

Willis, B. (1993). Distance Education: A practical guide. Englewood Cliffs NJ: Educational Technology Publications. Retrieved August 19, 2002, from http://www.uidaho.edu/eo/dist8.html. 